\title{
Prevalence and control of high blood pressure in primary care-results from the German metabolic and cardiovascular risk study (GEMCAS)
}

\author{
Chakrapani Balijepalli ${ }^{1,2}$, Peter Bramlage ${ }^{3}$, Christian Lösch ${ }^{1}$, Claudia Zemmrich ${ }^{3}$, Karin H Humphries ${ }^{2}$ and \\ Susanne Moebus ${ }^{1}$
}

Contemporary epidemiological data on blood pressure readings, hypertension prevalence and control in unselected patient populations covering a broad age range are scarce. The aim here is to report the prevalence of high blood pressure and to identify factors associated with blood pressure control in a large German primary care sample. We used data from the German Metabolic and Cardiovascular Risk Study including 35869 patients aged 18-99 years. High blood pressure was defined as systolic blood pressure $\geqslant 140 \mathrm{~mm} \mathrm{Hg}$ and/or diastolic blood pressure $\geqslant 90 \mathrm{~mm} \mathrm{Hg}$ or using antihypertensive therapy. Factors associated with blood pressure control among patients receiving antihypertensive therapy were examined using multiple logistic regressions to estimate odds ratios and $95 \%$ confidence intervals. The prevalence of high blood pressure, uncontrolled high blood pressure and untreated high blood pressure was $54.8 \%, 21.3 \%$ and $17.6 \%$, respectively. Age $>50$ years $(1.52 ; 1.40-$ $1.65)$, male sex $(1.30 ; 1.20-1.41)$, elevated waist circumference $(1.55 ; 1.45-1.65)$, high cholesterol $(1.24 ; 1.16-1.33)$, high triglycerides $(1.11 ; 1.04-1.19)$ and concomitant diabetes $(1.29 ; 1.20-1.40)$ were independently associated with uncontrolled high blood pressure. In a majority of patients we observed hypertension despite treatment for high blood pressures. Studies examining the reasons for treatment failure are highly warranted. Hypertension Research (2014) 37, 580-584; doi:10.1038/hr.2014.40; published online 13 March 2014

Keywords: cardiovascular disease; epidemiology; Germany; primary care; high blood pressure

\section{INTRODUCTION}

Hypertension is an important global public health challenge, and its role in cardiovascular as well as chronic kidney disease is well established. ${ }^{1}$ In 2010, hypertension was the leading risk factor for the global disease burden. ${ }^{2}$ Although there are a number of epidemiological studies on the prevalence of hypertension, ${ }^{3-8}$ contemporary epidemiological data on blood pressure readings and hypertension prevalence in large, unselected patient populations in primary care is lacking. ${ }^{9-13}$ Furthermore, only a few studies examined the comorbidity burden and risk factor profile of patients with or without hypertension in primary care. These data are necessary to understand the avoidable risk burden of hypertension in primary care and to find ways to alleviate this. On the basis of 35869 participants from the German Metabolic and Cardiovascular Risk Study (GEMCAS), we aimed to provide data on the prevalence of high blood pressure, hypertension treatment and to identify the factors associated with blood pressure control in a large German primary care sample.

\section{METHODS}

Study design

GEMCAS was a Germany-wide, cross-sectional study conducted for 2 weeks in October 2005 at 1511 randomly selected primary care practices. The methods have previously been described in detail. ${ }^{13}$ Briefly, we included all eligible individuals aged 18-99 visiting a general practitioner during these 2 weeks, regardless of the reason for their visit. Specialists in cardiology and diabetes were excluded. All participants gave written informed consent, and the institutional ethics committee approved the study protocol.

\section{Data collection}

The medical questionnaire, completed by the physician, provided details of age, reason for attendance, medication use, coexisting clinical conditions including cardiovascular diseases (CVDs) and diabetes mellitus. Anthropometric measurements were performed by the physician/assistant and were furnished in the medical questionnaire. The patient questionnaire included relevant information on medication use, lifestyle related and socio-demographic variables.

${ }^{1}$ Institute for Medical Informatics, Biometry and Epidemiology, University Hospital of Essen, University Duisburg-Essen, Essen, Germany; ${ }^{2}$ Providence Health Care Research Institute, University of British Columbia, Vancouver, British Columbia, Canada and ${ }^{3}$ Institute for Pharmacology and Preventive Medicine, Mahlow, Germany

Correspondence: Professor Dr S Moebus, Center for Urban Epidemiology, Institute for Medical Informatics, Biometry and Epidemiology, University Hospital of Essen, University Duisburg-Essen, 45122 Essen, Germany.

E-mail: susanne.moebus@uk-essen.de

Received 21 October 2013; revised 19 November 2013; accepted 12 December 2013; published online 13 March 2014 


\section{Blood pressure measurements}

Blood pressure was measured using commonly available equipment in the physician's practice and the type of device used (manual, automatic, brand name) was reported by the physicians. The readings for blood pressure were obtained after a 5-min rest with the participant in a sitting position. Accepted epidemiological standards for blood pressure measurements such as double measurement with at least 2 min of recovery between measurements were not feasible. However, the measurements represent standard physician practice procedures.

\section{Data quality assurance}

We implemented a comprehensive quality assurance evaluation by means of a special monitoring concept comprising telephone monitoring and random onsite visits, which have been described in detail in the recent past. ${ }^{14}$ In brief, the study was planned and conducted according to the German guidelines for Good Epidemiological Practice. ${ }^{15}$ A special monitoring system was designed to evaluate systematic errors and to ensure that data was obtained in a proper manner. Telephone monitoring was carried out at around $50 \%$ of the enrolled practices before the day of survey to make sure that the participating physicians understood the operating procedures and also had all the relevant materials in the form of questionnaires, other documents and blood-sampling materials needed for the study. After the phone call, the interviewers rated the monitored site based on the interview results. Random on-site visits were performed at around $10 \%$ of the participating medical practices during the day of survey. These practices were chosen at random before the survey. Special emphasis was placed on sites that received a poor rating during telephone monitoring, with such practices being included in the list for on-site monitoring during the survey day. ${ }^{13}$

\section{Blood pressure classification}

The readings were classified according to the 2013 European Society of Hypertension-European Society of Cardiology guidelines for the management of arterial hypertension. ${ }^{16}$ High blood pressure was defined as systolic blood pressure (SBP) $\geqslant 140 \mathrm{~mm} \mathrm{Hg}$ and/or diastolic blood pressure (DBP) $\geqslant 90 \mathrm{~mm} \mathrm{Hg}$ or using antihypertensive therapy. Treated and uncontrolled high blood pressure was defined as SBP $\geqslant 140 \mathrm{~mm} \mathrm{Hg}$ and/or DBP $\geqslant 90 \mathrm{~mm} \mathrm{Hg}$ and using antihypertensive therapy, and untreated high blood pressure was defined as SBP $\geqslant 140 \mathrm{~mm} \mathrm{Hg}$ and/or DBP $\geqslant 90 \mathrm{~mm} \mathrm{Hg}$ and not using antihypertensive therapy.

\section{Statistical analyses}

Of the 35869 study participants, we excluded for the present analysis those with missing data for blood pressure $(n=186)$, leaving a study sample of 35683 (mean age $51.7 \pm 16.1$ years, $61.2 \%$ women). Means and s.d. of SBP and DBP were computed for the overall study population and stratified by CVD risk factors. In the same analyses, prevalence of high blood pressure, treated and uncontrolled high blood pressure, and untreated high blood pressure were computed for the overall study population, as well as the subgroups with CVD risk factors.

\section{Logistic regressions}

Univariate regressions were modeled to estimate the associations between the outcome 'treated and uncontrolled high blood pressure' and various clinically relevant cardiovascular risk factors as possible predictors. The predictors included old age ( $>50$ years), sex, high waist circumference $(>102 \mathrm{~cm}$ in men; $>88 \mathrm{~cm}$ in women), high total cholesterol ( $\left.>200 \mathrm{mg} \mathrm{dl}^{-1}\right)$, low high-density lipoprotein cholesterol $\left(<40 \mathrm{mg} \mathrm{dl}^{-1}\right.$ in men, $<50 \mathrm{mg} \mathrm{dl}^{-1}$ in women), high triglycerides $\left(>150 \mathrm{mg} \mathrm{dl}^{-1}\right)$, smoking habit (current, past and never smokers), usage of lipid-lowering medications, history of CVD and diabetes. All predictors in the univariate regression were subsequently included in the multivariable logistic regression model to obtain the adjusted odds ratios with their 95\% confidence intervals. Statistical software SAS (Version 9.3) was used for the analyses (SAS Institute, Cary, NC, USA).

\section{RESULTS}

\section{Prevalence of high blood pressure}

A normal blood pressure was noticed on measurement in $54.8 \%$ men and $65.1 \%$ women, whereas $45.2 \%$ men and $34.9 \%$ women had high blood pressure (data not shown). The mean SBP and DBP, the proportion of high blood pressure, treated and uncontrolled high blood pressure, and untreated high blood pressure patients according to CVD risk factor status are presented in Table 1. The overall prevalence of high blood pressure was $54.8 \%$ for treated and uncontrolled $21.3 \%$ and for untreated high blood pressure $17.6 \%$. As expected, mean SBP increased with age, increasing body mass index and increasing waist circumference. Current smokers had a lower mean SBP $(126.2 \pm 17.9 \mathrm{~mm} \mathrm{Hg})$ when compared with never smokers $(131.3 \pm 19.3 \mathrm{~mm} \mathrm{Hg})$ and past smokers $(132.5 \pm 19.0 \mathrm{~mm}$ $\mathrm{Hg})$. Nearly a quarter of all men and a fifth of all women had high blood pressure despite treatment and $21 \%$ men (15.5\% women) were not treated despite high blood pressure. The proportion of the patients with high blood pressure despite treatment rose from $6.5 \%$ in the youngest age group to $49.5 \%$ in the oldest age group. Nearly a quarter of non-smokers and past smokers had high blood pressures despite treatment. Nearly half of all the patients with a history of CVD had high blood pressures despite treatment. Of all the patients who had a history of CVD nearly 7\% were not treated with any antihypertensive therapy, although their blood pressures were higher than normal (Table 1).

\section{Factors associated with blood pressure control}

Univariate regressions showed that older age ( $>50$ years), high waist circumference ( $>102 \mathrm{~cm}$ in men, $>88 \mathrm{~cm}$ in women), high total cholesterol $\left(>200 \mathrm{mg} \mathrm{dl}^{-1}\right)$, high triglycerides $\left(>150 \mathrm{mg} \mathrm{dl}^{-1}\right)$ and concomitant diabetes were associated with uncontrolled high blood pressure (Table 2). Whereas, smoking habit (both past and current), usage of lipid-lowering medications and a history of CVD were associated with a good blood pressure control. A lowered high-density lipoprotein cholesterol $\left(<40 \mathrm{mg} \mathrm{dl}^{-1}\right.$ in men, $<50 \mathrm{mg} \mathrm{dl}^{-1}$ in women) was not associated (odds ratios 0.97 (0.93-1.02)) with blood pressure control (Table 2).

In the multivariable logistic regression, age ( $>50$ years) (1.52; $1.40-1.65)$, male sex $(1.30 ; 1.20-1.41)$, high waist circumference (1.55; $1.45-1.65)$, high total cholesterol (1.24; 1.16-1.33), high triglycerides $(1.11 ; 1.04-1.19)$ and concomitant diabetes (1.29; 1.20-1.40) remained independently associated with uncontrolled high blood pressure. In contrast, concomitant lipid-lowering therapy $(0.85 ; 0.79$ $0.92)$, a history of CVD $(0.81 ; 0.76-0.87)$ and past smoking habit $(0.84 ; 0.78-0.90)$ as well as current smoking habit $(0.81 ; 0.74-0.88)$ was associated with good control of blood pressure by pharmacological treatment. As observed in the univariate regression, even in the multivariable regression, lowered high-density lipoprotein cholesterol was not associated $(0.96 ; 0.88-1.03)$ with blood pressure control (Table 2).

\section{DISCUSSION}

Overall, the prevalence of high blood pressure was 54.8\% $(62.8 \%$ men; $49.7 \%$ women). Nearly a fifth of all the patients $(24.3 \%$ men; $19.4 \%$ women) had high blood pressures despite antihypertensive treatment. A substantial proportion of patients (21\% men; $15.5 \%$ women) were not treated for blood pressure despite their blood pressures being higher than normal. Old age (age $>50$ years), elevated waist circumference ( $>102 \mathrm{~cm}$ in men, $>88 \mathrm{~cm}$ in women), high total cholesterol $\left(>200 \mathrm{mg} \mathrm{dl}^{-1}\right)$, high triglycerides $\left(>150 \mathrm{mg} \mathrm{dl}^{-1}\right)$ and concomitant diabetes were independently 
Table 1 Characteristics of patients by SBP and DBP, prevalence of high BP, treated and uncontrolled high BP, and untreated high BP

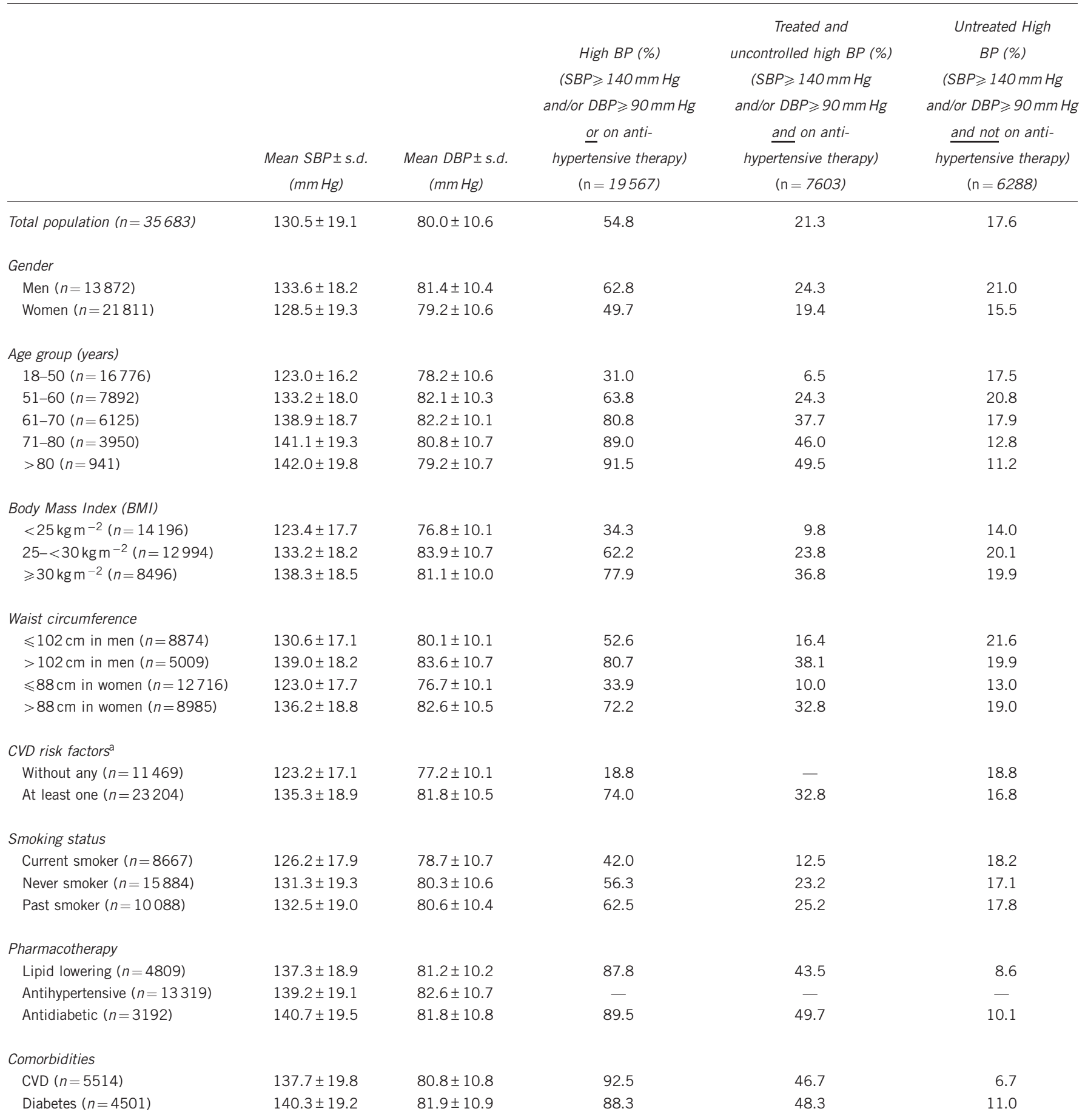

Abbreviations: BP, blood pressure; CVD, cardiovascular disease; DBP, diastolic BP; HDL, high-density lipoprotein; SBP, systolic BP.

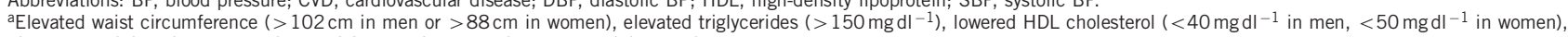
diabetes, antidiabetic therapy, history of CVD, antihypertensive therapy, lipid-lowering therapy.

associated with a poor blood pressure control in both sexes despite pharmacological treatment. Whereas smoking habit, usage of lipidlowering medications and a history of CVD were independently associated with a good blood pressure control in both sexes.

High blood pressure prevalence in primary care

Our results were comparable to previous studies conducted in Germany as well as in other countries. ${ }^{9} 13$ Sharma et al. ${ }^{9}$ have studied the prevalence and control of hypertension in Germany using the HYDRA study, and they have shown that the prevalence of hypertension in the German primary care was nearly 52\% when hypertension was defined as either current blood pressure $\geqslant 140 /$ $90 \mathrm{~mm} \mathrm{Hg}$ and/or usage of antihypertensive medication. Their results were almost similar to our results using the same definition for hypertension. Furthermore, Sharma et al. have shown that according to the doctor's treatment description appraisal, $16 \%$ of the patients 
Table 2 Factors associated with poor blood pressure control among patients receiving antihypertensive therapy

\begin{tabular}{|c|c|c|}
\hline & \multicolumn{2}{|c|}{ Odds ratios $(95 \% \mathrm{Cl})$} \\
\hline & Univariate & Multivariate \\
\hline Age $>50$ years & $1.55(1.46-1.65)$ & $1.52(1.40-1.65)$ \\
\hline Men vs women & $1.05(1.00-1.10)$ & $1.30(1.20-1.41)$ \\
\hline Waist circumference ${ }^{a}$ & $1.61(1.54-1.67)$ & $1.55(1.45-1.65)$ \\
\hline High total cholesterol ${ }^{\mathrm{b}}$ & $1.29(1.24-1.35)$ & $1.24(1.16-1.33)$ \\
\hline Low HDLc & $0.97(0.93-1.02)$ & $0.96(0.88-1.03)$ \\
\hline High triglycerides $^{d}$ & $1.26(1.20-1.31)$ & $1.11(1.04-1.19)$ \\
\hline Past smoker ${ }^{\mathrm{e}}$ & $0.89(0.84-0.93)$ & $0.84(0.78-0.90)$ \\
\hline Current smokere & $0.76(0.71-0.81)$ & $0.81(0.74-0.88)$ \\
\hline Lipid-lowering medications & $0.88(0.84-0.92)$ & $0.85(0.79-0.92)$ \\
\hline CVD history & $0.84(0.80-0.88)$ & $0.81(0.76-0.87)$ \\
\hline Diabetes & $1.35(1.28-1.42)$ & $1.29(1.20-1.40)$ \\
\hline
\end{tabular}

Abbreviations: $\mathrm{Cl}$, confidence interval; $\mathrm{CVD}$, cardiovascular disease; $\mathrm{HDL}$, high-density lipoprotein.

aWaist circumference ( $>102 \mathrm{~cm}$ in men, $>88 \mathrm{~cm}$ in women).

bTotal cholesterol $>200 \mathrm{mg} \mathrm{dl}^{-1}$.

CHDL cholesterol ( $<40 \mathrm{mg} \mathrm{dl}^{-1}$ in men, $<50 \mathrm{mg} \mathrm{dl}^{-1}$ in women).

'Triglycerides $>150 \mathrm{mg} \mathrm{dl}^{-1}$.

e‘Never smoked' group was the reference.

with high blood pressure were not treated and $43 \%$ patients did not have control over blood pressure despite treatment. Our results with respect to untreated patients were in concordance with the results of Sharma et al. ${ }^{9}$ Godet-Mardirossian et al. ${ }^{12}$ have studied the hypertension prevalence and management in the French population aged between 18 and 74 years, in which they reported a hypertension prevalence of $31 \%$ and control of nearly $26 \%$. In our study, the prevalence of high blood pressure was higher than that in the French study at $54.8 \%$, the control was also higher at $42.7 \%$, when we restricted our analyses to the 18-74 year age group, the high blood pressure prevalence was $51.5 \%$ and the control was $43.4 \%$. These differences in hypertension prevalence and control in the two populations could be attributed to the difference in the prevalence of determinants of hypertension, such as dietary habits, physical activity, obesity so on., in the two populations as well as differences in the treatment approaches in the two countries with more difficulty to treat cases in the French group. ${ }^{12}$ Tocci et al. ${ }^{13}$ have reviewed the published data about blood pressure control in Italy, and reported that the blood pressure control rates were nearly $41 \%$ in three surveys performed by general practitioners; the control rates reported by Tocci et al. were similar to the control rates in our study.

\section{The role of antihypertensive treatment}

We identified a set of risk factors associated with a lack of blood pressure control despite antihypertensive therapy. Amongst them were typical risk factors for hypertension, such as age, high waist circumference, high total cholesterol, high triglycerides and diabetes. The role of age in the control of blood pressure has been widely discussed. As in our study, other studies also showed that blood pressure control declines with age, resulting in higher rates of uncontrolled hypertension among the elderly. ${ }^{17-19}$ Our study showed that increase in waist circumference is associated with poor control of blood pressure. This phenomenon was also noted in other studies. ${ }^{20-22}$ Our study showed that high total cholesterol and high triglycerides were associated with a poor BP control, and previous studies from diverse populations also demonstrated that hypertensive patients were more likely to have lipid abnormalities. ${ }^{23-27}$
Like several other epidemiological studies conducted worldwide, our study also showed that current smokers have a lower BP level compared with non-smokers and past smokers. ${ }^{28-32}$ Another important aspect is the increased prevalence of hypertension noted among past smokers. This may be associated with the documented rise in body weight that occurs with smoking cessation ${ }^{33,34}$ and the effects of the weight gain on hypertension.

Among those receiving antihypertensive pharmacotherapy when classified according to the JNC 7 classification of blood pressure, ${ }^{35}$ only $7 \%$ were normotensive, $36 \%$ remained in the pre-hypertensive range (SBP $120-139 \mathrm{~mm} \mathrm{Hg}$ or DBP $80-89 \mathrm{~mm} \mathrm{Hg}$ ) and $57 \%$ had at least a blood pressure of SBP $\geqslant 140 \mathrm{~mm} \mathrm{Hg}$ and/or DBP $\geqslant 90 \mathrm{~mm} \mathrm{Hg}$ despite treatment (data not shown). This is surprising, although not new, ${ }^{9,36}$ given the high efficacy of antihypertensive drugs in randomized controlled trials. It is apparent, however, that blood pressure lowering does not work as well in clinical practice as in the trials. This has been attributed to a low compliance and a low persistence with treatment. ${ }^{37}$ Likewise, it has been attributed to considerable comorbidity as evident in elderly patients in which polypharmacy may contribute to a lesser blood pressure effect because of drug interactions ${ }^{38}$ and to some hesitancy in lowering blood pressure in the elderly because of a fear of falls. ${ }^{39,40}$

\section{Limitations}

Several limitations have to be noted. (1) BP was only measured on a single occasion using standard primary practice methodology, which may result in an overestimation of the true prevalence of hypertension. It has been shown that 'although a single BP measurement does not characterize an individual well, accurate group means can still be obtained with a single reading taken under appropriate conditions. ${ }^{5}$ Furthermore, recent studies suggest that even in those being normotensive during a regular office visit might be actually hypertensive during $24 \mathrm{~h}$ measurements, particularly because of elevations of blood pressure at night (non or inverted dipping). ${ }^{41,42}$ (2) It is also important to note that we primarily selected nonspecialist offices for this survey. It is reasonable to expect a substantial proportion of patients with more severe hypertension will be seen in subspeciality clinics, including cardiology, nephrology or diabetology; therefore, the total burden of hypertensive patients seen in ambulatory care may be larger than observed in GEMCAS. The inclusion of patients was done consecutively, irrespective of the primary reason for physician's contact. Because of the nature of the sample chosen for the study, a bias due to different underlying diseases in the patients included in the study should be assumed, but the direction and magnitude of that bias cannot be evaluated. (3) With regard to treatment, we did not differentiate between non-pharmacological and pharmacological treatment approaches, as often a combination of both was used. In the analyses, however, only the pharmacological treatment was evaluated.

\section{CONCLUSIONS}

Our study showed that more than half $(54.8 \%)$ of adult German primary care attendees were having high blood pressure. Nearly $21 \%$ of all the primary care attendees from our survey had uncontrolled high blood pressure and nearly $18 \%$ of all patients from our survey were not taking any antihypertensive medication despite having high blood pressure. Traditional cardiovascular risk factors like old age, high total cholesterol, high triglycerides and diabetes were associated with poor blood pressure control in both sexes. These data suggest that high blood pressure is highly prevalent in Germany. Despite treatment, a substantial proportion of patients did not show blood 
pressure control, and studies looking into reasons for treatment failures are warranted.

\section{CONFLICT OF INTEREST}

$\mathrm{P} B$ received research funding and consultancy honoraria from a number of pharmaceutical companies producing antihypertensive drugs. The remaining authors declare no conflict of interest.

\section{ACKNOWLEDGEMENTS}

We would like to thank the physicians and their personnel involved in the study for their contribution. Also, we are indebted to all study participants for their kind cooperation in examinations and interviews. GEMCAS was supported by an unrestricted educational research grant from Sanofi Aventis Deutschland GmbH, Berlin, Germany.

1 Whelton PK. Epidemiology of hypertension. Lancet 1994; 344: 101-106. (Review).

2 Lim SS, Vos T, Flaxman AD, Danaei G, Shibuya K, Adair-Rohani H. A comparative risk assessment of burden of disease and injury attributable to 67 risk factors and risk factor clusters in 21 regions, 1990-2010: a systematic analysis for the Global Burden of Disease Study 2010. Lancet 2012; 380: 2224-2260.

3 Kearney PM, Whelton M, Reynolds K, Muntner P, Whelton PK, He J. Global burden of hypertension: analysis of worldwide data. Lancet 2005; 365: 217-223.

4 Cutler JA, Sorlie PD, Wolz M, Thom T, Fields LE, Roccella EJ. Trends in hypertension prevalence, awareness, treatment, and control rates in United States adults between 1988-1994 and 1999-2004. Hypertension 2008; 52: 818-827.

5 Wolf-Maier K, Cooper RS, Banegas JR, Giampaoli S, Hense HW, Joffres M, Kastarinen M, Poulter N, Primatesta P, Rodríguez-Artalejo F, Stegmayr B, Thamm M, Tuomilehto J, Vanuzzo D, Vescio F. Hypertension prevalence and blood pressure level in 6 European countries, Canada, and the United States. JAMA 2003; 289 2363-2369.

6 Erem C, Hacihasanoglu A, Kocak M, Deger O, Topbas M. Prevalence of prehypertension and hypertension and associated risk factors among Turkish adults: Trabzon Hypertension Study. J Public Health (Oxf) 2009; 31: 47-58.

7 Thamm M. Blutdruck in Deutschland- Zustandsbeschreibung und Trends. Gesund heitswesen 1999; 61: S90-S93. (Sonderheft 2).

8 Guo F, He D, Zhang W, Walton RG. Trends in prevalence, awareness, management, and control of hypertension among United States adults, 1999 to 2010. J Am Coll Cardiol 2012; 60: 599-606.

9 Sharma AM, Wittchen HU, Kirch W, Pittrow D, Ritz E, Göke B, Lehnert H, Tschöpe D, Krause $P$, Höfler M, Pfister H, Bramlage P, Unger THYDRA Study Group. High prevalence and poor control of hypertension in primary care: cross-sectional study. $J$ Hypertens 2004; 22: 479-486.

10 Thoenes M, Tebbe U, Rosin L, Paar WD, Bramlage P, Kirch W, Böhm M. Blood pressure management in a cohort of hypertensive patients in Germany treated by cardiologists. Clin Res Cardiol 2011; 100: 483-491.

11 Bramlage P, Bohm M, Volpe M, Khan BV, Paar WD, Tebbe U, Thoenes M. A global perspective on blood pressure treatment and control in a referred cohort of hypertensive patients. J Clin Hypertens (Greenwich) 2010; 12: 666-677.

12 Godet-Mardirossian H, Girerd X, Vernay M, Chamontin B, Castetbon K, de Peretti C. Patterns of hypertension management in France (ENNS 2006-2007). Eur J Prev Cardiol 2012; 2: 213-220.

13 Tocci G, Rosei EA, Ambrosioni E, Borghi C, Ferri C, Ferrucci A, Mancia G, Morganti A, Pontremoli R, Trimarco B, Zanchetti A, Volpe M. Blood pressure control in Italy: analysis of clinical data from 2005-2011 surveys on hypertension. J Hypertens 2012; 30: 1065-1074.

14 Moebus S, Hanisch J, Neuhaeuser M, Aidelsburger P, Wasem J, Joeckel K-. Assessing the prevalence of the Metabolic Syndrome according to NCEP ATP III in Germany: feasibility and quality aspects of a two step approach in 1550 randomly selected primary health care practices. Ger Med Sci 2006; 4: Doc07.

15 Hoffmann W, Latza U, Terschuren C. [Guidelines and recommendations for ensuring Good Epidemiological Practice (GEP) - revised version after evaluation]. Gesundheits wesen 2005; 67: 217-225.

16 Mancia G, Fagard R, Narkiewicz K, Redon J, Zanchetti A, Böhm M, Christiaens T, Cifkova R, De Backer G, Dominiczak A, Galderisi M, Grobbee DE, Jaarsma T, Kirchhof P, Kjeldsen SE, Laurent S, Manolis AJ, Nilsson PM, Ruilope LM, Schmieder RE, Sirnes PA, Sleight P, Viigimaa M, Waeber B, Zannad F, Redon J, Dominiczak A, Narkiewicz K, Nilsson PM, Burnier M, Viigimaa M, Ambrosioni E, Caufield $M$, Coca A, Olsen MH, Schmieder RE, Tsioufis $C$, van de Borne $P$, Zamorano JL, Achenbach S, Baumgartner H, Bax JJ, Bueno H, Dean V, Deaton C Erol C, Fagard R, Ferrari R, Hasdai D, Hoes AW, Kirchhof P, Knuuti J, Kolh P, Lancellotti P, Linhart A, Nihoyannopoulos P, Piepoli MF, Ponikowski P, Sirnes PA Tamargo JL, Tendera M, Torbicki A, Wijns W, Windecker S, Clement DL, Coca A Gillebert TC, Tendera M, Rosei EA, Ambrosioni E, Anker SD, Bauersachs J, Hitij JB, Caulfield M, De Buyzere M, De Geest S, Derumeaux GA, Erdine S, Farsang C,
Funck-Brentano C, Gerc V, Germano G, Gielen S, Haller H, Hoes AW, Jordan J, Kahan T, Komajda M, Lovic D, Mahrholdt H, Olsen MH, Ostergren J, Parati G, Perk J, Polonia J, Popescu BA, Reiner Z, Rydén L, Sirenko Y, Stanton A, Struijker-Boudier H, Tsioufis C, van de Borne P, Vlachopoulos C, Volpe M, Wood DA 2013ESH/ESC guidelines for the management of arterial hypertension: the Task Force for the Management of Arteria Hypertension of the European Society of Hypertension (ESH) and of the European Society of Cardiology (ESC). Eur Heart J 2013; 34: 2159-2219.

17 Hajjar I, Kotchen TA. Trends in prevalence, awareness, treatment, and control of hypertension in the United States, 1988-2000. JAMA 2003; 290: 199-206.

18 Hyman DJ, Pavlik VN. Characteristics of patients with uncontrolled hypertension in the United States. New Engl J Med 2001; 345: 479-486.

19 Lloyd-Jones DM, Evans JC, Larson MG, O'Donnell CJ, Roccella EJ, Levy D. Differentia control of systolic and diastolic blood pressure: factors associated with lack of blood pressure control in the community. Hypertension 2000; 36: 594-599.

20 Okosun IS, Cooper RS, Rotimi CN, Osotimehin B, Forrester T. Association of waist circumference with risk of hypertension and type 2 diabetes in Nigerians, Jamaicans, and African-Americans. Diabetes Care 1998; 21: 1836-1842.

21 Okosun IS, Prewitt TE, Cooper RS. Abdominal obesity in the United States: prevalence and attributable risk of hypertension. J Hum Hypertens 1999; 13: 425-430.

22 Warren TY, Wilcox S, Dowda M, Baruth M. Independent association of waist circumference with hypertension and diabetes in African American women, South Carolina, 2007-2009. Prev Chronic Dis 2012; 9: E105.

23 Wannamethee SG, Shaper AG, Durrington PN, Perry IJ. Hypertension, serum insulin, obesity and the metabolic syndrome. J Hum Hypertens 1998; 12: 735-741.

24 Nanchahal K, Ashton WD, Wood DA. Association between blood pressure, the treatment of hypertension, and cardiovascular risk factors in women. $J$ Hypertens 2000; 18: 833-841.

25 Ishikawa S, Shibano Y, Asai Y, Kario K, Kayaba K, Kajii E. Blood pressure categories and cardiovascular risk factors in Japan: the Jichi Medical School (JMS) Cohort Study. Hypertens Res 2007; 30: 643-649.

26 Asmar R, Vol S, Pannier B, Brisac AM, Tichet J, El Hasnaoui A. High blood pressure and associated cardiovascular risk factors in France. J Hypertens 2001; 19 1727-1732.

27 Barrios V, Escobar C, Calderón A, Llisterri JL, Echarri R, Alegría E, Muñiz J, Matalí A. Blood pressure and lipid goal attainment in the hypertensive population in the primary care setting in Spain. J Clin Hypertens (Greenwich) 2007; 9: 324-329.

28 Seltzer CC. Effect of smoking on blood pressure. Am Heart J 1974; 87: 558-564.

29 Savdie E, Grosslight GM, Adena MA. Relation of alcohol and cigarette consumption to blood pressure and serum creatinine levels. J Chronic Dis 1984; 37: 617-623.

30 Benowitz NL, Sharp DS. Inverse relation between serum cotinine concentration and blood pressure in cigarette smokers. Circulation 1989; 80: 1309-1312.

31 Imamura H, Tanaka K, Hirae C, Futagami T, Yoshimura Y, Uchida K, Tanaka A, Kobata D. Relationship of cigarette smoking to blood pressure and serum lipids and lipoproteins in men. Clin Exp Pharmacol Physiol 1996; 23: 397-402.

32 Primatesta P, Falaschetti E, Gupta S, Marmot MG, Poulter NR. Association between smoking and blood pressure: evidence from the health survey for England. Hypertension 2001; 37: 187-193.

33 Kasteridis P, Yen ST. Smoking cessation and body weight: evidence from the Behavioral Risk Factor Surveillance Survey. Health Serv Res 2012; 47: 1580-1602.

34 Williamson DF, Madans J, Anda RF, Kleinman JC, Giovino GA, Byers T. Smoking cessation and severity of weight gain in a national cohort. New Engl J Med 1991; 324 739-745.

35 Chobanian AV, Bakris GL, Black HR, Cushman WC, Green LA, Izzo Jr JL, Jones DW Materson BJ, Oparil S, Wright Jr JT, Roccella EJNational Heart, Lung, and Blood Institute Joint National Committee on Prevention, Detection, Evaluation, and Treatment of High Blood Pressure; National High Blood Pressure Education Program Coordinating Committee. The Seventh Report of the Joint National Committee on Prevention, Detection, Evaluation, and Treatment of High Blood Pressure: the JNC 7 report. JAMA 2003; 289: 2560-2572.

36 Thoenes M, Bramlage P, Zhong S, Shang S, Volpe M, Spirk D. Hypertension control and cardiometabolic risk: a regional perspective. Cardiol Res Pract 2012; 2012: 925046.

37 Bramlage P, Hasford J. Blood pressure reduction, persistence and costs in the evaluation of antihypertensive drug treatment-a review. Cardiovasc Diabetol 2009; 8: 18. Review.

38 Goswami SK, Jain S, Chudasama H, Santani D. Potential pharmacodynamic drug-drug interaction between concomitantly administered lisinopril and diclofenac sodium: a call for appropriate management in hypertensive osteoarthritic patients. Drug Metabo Drug Interact 2011; 26: 127-137.

39 Schall $\mathrm{P}$, Wehling $\mathrm{M}$. Treatment of arterial hypertension in the very elderly: a metaanalysis of clinical trials. Arzneimittelforschung 2011; 61: 221-228.

40 Steinman MA, Handler SM, Gurwitz JH, Schiff GD, Covinsky KE. Beyond the prescription: medication monitoring and adverse drug events in older adults. J Am Geriatr Soc 2011: 59: 1513-1520.

41 Scholze J, Bramlage P, Trenkwalder P, Kreutz R. Efficacy and safety of a fixed-dose combination of lercanidipine and enalapril in daily practice. A comparison of office, self-measured and ambulatory blood pressure. Expert Opin Pharmacother 2011; 12 2771-2779.

42 Mengden T, Hubner R, Bramlage P. Office and ambulatory blood pressure control with a fixed-dose combination of candesartan and hydrochlorothiazide in previously uncontrolled hypertensive patients: results of CHILI CU Soon. Vasc Health Risk Manag 2011; 7: 761-769. 